\title{
Histamine, a vasoactive agent with vascular disrupting potential, improves tumour response by enhancing local drug delivery
}

\author{
F Brunstein*,', J Rens', ST van Tiel', AMM Eggermont' and TLM ten Hagen' \\ 'Laboratory of Experimental Surgical Oncology, Erasmus MC, Department of Surgical Oncology, Daniel den Hoed Cancer Centre, Room Ee 0175 , \\ PO Box 1738-3000 DR Rotterdam, The Netherlands
}

\begin{abstract}
Tumour necrosis factor (TNF)-based isolated limb perfusion (ILP) is an approved and registered treatment for sarcomas confined to the limbs in Europe since 1998, with limb salvage indexes of 76\%. TNF improves drug distribution in solid tumours and secondarily destroys the tumour-associated vasculature (TAV). Here we explore the synergistic antitumour effect of another vasoactive agent, histamine (Hi), in doxorubicin (DXR)-based ILP and evaluate its antivascular effects on TAV. We used our well-established rat ILP model for in vivo studies looking at tumour response, drug distribution and effects on tumour vessels. In vitro studies explored drug interactions at cellular level on tumour cells (BN- I75) and Human umbilical vein endothelial cells (HUVEC). There was a I7\% partial response and a 50\% arrest in tumour growth when $\mathrm{Hi}$ was combined to DXR, without important side effects, against $100 \%$ progressive disease with DXR alone and 29\% arrest in tumour growth for Hi alone. Histology documented an increased DXR leakage in tumour tissue combined to a destruction of the TAV, when Hi was added to the ILP. In vitro no synergy between the drugs was observed. In conclusion, $\mathrm{Hi}$ is a vasoactive drug, targeting primarily the TAV and synergises with different chemotherapeutic agents. British Journal of Cancer (2006) 95, 1663- 1669. doi: I0.1038/sj.bjc.660346I www.bjcancer.com
\end{abstract}

Published online 14 November 2006

(C) 2006 Cancer Research UK

Keywords: regional treatment; histamine; doxorubicin; TAV; soft-tissue sarcomas

Tumour necrosis factor (TNF)-based isolated limb perfusion (ILP) is an approved and registered treatment for sarcomas confined to the limb in Europe since 1998 and is currently carried out in approximately 30 cancer centres with referral programmes for limb salvage around the continent (Eggermont et al, 1996a). Isolated limb perfusion with TNF and melphalan also yields excellent antitumour effects against melanoma (Lienard et al, 1992) and various other tumours in the clinical setting (Bickels et al, 1999; Olieman et al, 1999; Eggermont et al, 2003). The mechanism of action is based on the vasoactive effects of TNF, leading to a significant enhancement of tumour-selective melphalan uptake (de Wilt et al, 2000) and secondarily to a complete destruction of tumour vasculature (Eggermont et al, 1996b).

An important drawback of the use of TNF is its highly toxic nature mandating strict monitoring of leakage to the systemic compartment during ILP. Moreover, this toxic profile of TNF limits expansion of its use to less controllable sites. Therefore, other possible vasoactive drugs were sought and tested in our preclinical rat ILP model as potential candidates (Brunstein $e t a l$, 2004; Hoving et al, 2005). In this perspective, we showed strong synergy of histamine (Hi), an inflammatory mediator, when combined to melphalan in ILP, including a $66 \%$ overall response rate (OR) with $33 \%$ complete responses (CR) (Brunstein et al, 2004).

\footnotetext{
*Correspondence: Dr F Brunstein;

E-mail: flis_br@yahoo.com

Revised 3 October 2006; accepted 4 October 2006; published online I4 November 2006
}

The aim of this study is to evaluate the effects of Hi on TAV by means of histological studies and also explore whether the synergistic effect of Hi would also apply to the combination with doxorubicin (DXR), an important chemotherapeutic drug in solid tumour treatment (Santoro et al, 1995; O'Byrne and Steward, 1999). Based on the assumption that DXR is the best single agent for systemic therapy, with activity in more than $20 \%$ of the treated patients, some Italian centres use it in the TNF-based ILP instead of melphalan, with circa $26 \%$ complete histologic necrosis (Rossi et al, 1999, 2005). Using the experimental ILP model in rats bearing syngenic soft-tissue sarcomas, the ability of the combined treatment to improve tumour response is evaluated. The effects of $\mathrm{Hi}$ on endothelial cells and TAV as well as on drug distribution are evaluated in vivo, taking advantage of the natural fluorescence of DXR and combining different histological stainings.

\section{MATERIALS AND METHODS}

\section{ILP protocol}

Male inbred Brown Norway rats were obtained from Harlan-CPB (Austerlitz, the Netherlands), weighing 250-300 g and were fed a standard laboratory diet ad libitum (Hope Farms Woerden, the Netherlands).

Small fragments $(3 \mathrm{~mm})$ of the syngeneic BN-175 sarcoma were inserted subcutaneously in the right hind leg of the animals as described previously (de Wilt et al, 1999). Tumour growth was measured daily with a calipre and the volume was calculated using the formula $0.4\left(A^{2} \times B\right)$ (where $B$ represents the largest tumour 
diameter and $A$ is the diameter perpendicular to it). When tumour diameter exceeded $25 \mathrm{~mm}$ rats were killed by cervical dislocation, under anaesthesia. At the end of the experiment all the rats were killed by the method specified.

The treatment consisted of the experimental ILP, as described previously (de Wilt et al, 1999). Briefly, 7-10 days after implantation, tumours reached a diameter between 12 and $15 \mathrm{~mm}$ and were amenable to the procedure. Under anaesthesia (intraperitoneal ketamine and intramuscular hypnomidate), the inguinal vessels were reached through an incision parallel to the inguinal ligament, canulated and connected via a roller pump to an oxygenated reservoir where drugs were added in boluses. A groin tourniquet occluded collateral vessels, warranting a proper isolation of the limb.

The $5 \mathrm{ml}$ total volume perfusate consisted of: haemaccel alone (Boehring Pharma, Amsterdam, the Netherlands); haemaccel $+400 \mu \mathrm{g}$ DXR $\left(80 \mu \mathrm{g} \mathrm{ml}^{-1}\right)$ (Adriablastina ${ }^{\mathbb{R}}$, Farmitalia Carlo Erba, Brussels, Belgium); haemaccel $+1000 \mu \mathrm{g} \mathrm{Hi}\left(200 \mu \mathrm{g} \mathrm{ml}^{-1}\right)$ (kindly provided by Maxim Pharmaceuticals Inc., San Diego, CA, USA) or haemaccel with $400 \mu \mathrm{g}$ DXR and $1000 \mu \mathrm{g}$ of Hi.

Tumour dimensions were measured every day for volume calculation. Response was classified as: progressive disease (PD), increase of more than $25 \%$; no change (NC), volume kept in the range of -25 to $+25 \%$; partial remission (PR), decrease between -25 to $-99 \%$ or complete response (CR), no palpable tumour, initial volume as compared to volume on day 9 .

Limb function was clinically observed as the ability to walk and stand on the perfused limb after ILP. On a scale from 0 to 2, grade 0 is a severely impaired function where the rat drags its hind limb; grade 1, a slightly impaired function (cannot use it in a normal way, but stand on it);and finally, grade 2 is an intact function (normal walking and standing pattern).

Locoregional toxicity was also evaluated by clinical observation of limb oedema. Oedema was defined as absent $(-)$, or present, and in this case graded in a scale from + to ++++ , according to the extent of increase in volume of the treated limb as compared to the opposite, not treated limb.

The studies were carried out in accordance with protocols approved by the Animal Care Committee of the Erasmus University Rotterdam, the Netherlands.

\section{Histologic evaluation after Hi-based ILP}

Two animals for each group were killed by cervical dislocation directly and $24 \mathrm{~h}$ after ILP, and tumours and a piece of underlying muscle were excised, fixed in $4 \%$ formaldehyde solution and embedded in paraffin. The slides were stained with haematoxylin and eosin and CD-31 by the Pathology Department of the Erasmus MC. Images were taken on a Leica DM-RXA microscope supplied with a Sony 3CCD DXC camera.

\section{Perls iron staining - histologic evaluation after Hi-based ILP}

Two animals for each group were killed by cervical dislocation 7 days after ILP, and tumours and a piece of adjacent muscle were excised, fixed in $4 \%$ formaldehyde solution and embedded in paraffin. The slides were stained by Perl's method, a qualitative technique based on the release of ferric iron from hemosiderin by acid treatment, forming ferric chloride. The ferric iron reacts with potassium ferrocyanide to form ferric ferrocyanide, an insoluble blue compound known as Prussian blue (Bancroft and Cook, 1984). Images were taken on a Leica DM-RXA microscope supplied with a Sony 3CCD DXC camera.

\section{DXR distribution and evaluation of vascular function}

To gain insight into in vivo intratumoral drug distribution, three animals for DXR alone and three for $\mathrm{Hi}+$ DXR were submitted to standard ILP plus the addition of $20 \mu \mathrm{l}$ of the vessel staining FITC-lectin (Bandeireae simplicifolia, BS-I Isolectin B4, Sigma, Zwijndrecth, the Netherlands) to the perfusate. Directly after the procedure, the animals were killed by cervical dislocation, tumours were excised, snap frozen in liquid nitrogen and stored at $-80^{\circ} \mathrm{C}$. Thick sections of $25 \mu \mathrm{m}$ were mounted with Mowiol and evaluated by confocal microscopy with a Zeiss LSM 510 Meta $(488 \mathrm{~nm}$ laser with 505-505 band pass filter (FITC) and $543 \mathrm{~nm}$ laser with 560 long-pass filter (DXR)). Nine different fields per animal were selected and photographed (three fields per slide, in a total of three slides per animal). Images were further processed, using Image Tool $^{\mathbb{R}}$ for Windows 2000. First, the colours of the images were separated, for quantification of vessel density (green) and drug distribution (red). Next, images were binarised, with a lower threshold setting based on the negative control, and percentage of positive pixels was determined. Data were plotted with GraphPad Prism for Windows 2000.

\section{Immunohistochemistry staining antialbumin}

For the evaluation of the presence of albumin extravasation into the tumour, two rats submitted to each of the following ILP: (1) sham; (2) DXR; (3) Hi or (4) Hi + DXR were included in this study. Tumours were excised, fixed in $4 \%$ formaldehyde solution and embedded in paraffin right after the ILP.

Sections were deparaffinised, rehydrated and treated with $10 \mathrm{~mm}$ sodium citrate buffer, $\mathrm{pH} 6.0$, at $100^{\circ} \mathrm{C}$ in a microwave oven for $10 \mathrm{~min}$. Next, the slides were washed and incubated with rabbitanti rat albumin (Nordic Immunological Laboratories, Tilburg, the Netherlands) at 1:1000 in Phosphate buffered saline (PBS), overnight at $4{ }^{\circ} \mathrm{C}$. After washing, antibody binding was detected using diaminobenzidine substrate-chromogen (Sigma-Aldrich, Zwijndrecth, the Netherlands) for $5 \mathrm{~min}$ at room temperature. Slides were counterstained with Mayer's haematoxylin, dehydrated with ethanol, cleared with xylene and finally mounted with Entellan (Merck, Darmstadt, Germany). Images were taken on a Leica DM-RXA microscope equipped with a Sony 3CCD DXC camera.

\section{Martius/scarlet/blue (MSB) for connective tissue and fibrin}

Two rats submitted to each of the following ILP: (1) sham, (2) DXR, (3) Hi or (4) Hi + DXR were included in this study. Tumours and underlining muscle were excised, fixed in $4 \%$ formaldehyde solution and embedded in paraffin right after the ILP. Tumour slides were first deparaffinised and hydrated before being stained by MSB method for fibrin. Shortly, slides were placed in Martius yellow (Sigma) for $2 \mathrm{~min}$, rinsed with distilled water; placed in Crystal scarlet (Ponceau 6R) (Sigma) for $10 \mathrm{~min}$; differentiated with Phosphotungstic acid (Sigma) until only fibrin was red (circa $10 \mathrm{~min}$ ); and placed in Methyl blue (Sigma) until collagen was blue (also circa $10 \mathrm{~min}$ ). Then, slides were briefly rinsed with $1 \%$ aqueous acetic acid, rapidly dehydrated with ethanol, cleared with xylene and finally mounted with Entellan (Merck). Images were taken on a Leica DM-RXA microscope equipped with a Sony 3CCD DXC camera.

\section{Cytotoxicity assay}

Direct interaction between DXR and Hi was evaluated in vitro on BN-175 tumour cells and endothelial cells.

BN-175 tumour cells (isolated from the spontaneous, rapidly growing and metastasizing soft-tissue sarcoma) (Kort et al, 1984) were grown in RPMI-1640 essential medium (Life Technologies, Breda, the Netherlands) supplemented with $10 \%$ foetal calf serum and $0.1 \%$ penicillin-streptomycin (Life Technologies, Breda, the Netherlands). 
Cells were plated $24 \mathrm{~h}$ before treatment in 96-well, flat-bottomed, microtitre plates (Costar, Cambridge, MA, USA) at a concentration of $10^{5}$ cells ml ${ }^{-1}$, final volume of $100 \mu \mathrm{l}$ and allowed to grow as a monolayer. Next, they were incubated at $37^{\circ} \mathrm{C}$ in $5 \% \mathrm{CO}_{2}$ for $48 \mathrm{~h}$ in the presence of medium alone or medium plus different concentrations of DXR and Hi. Histamine ranged from 0 to $200 \mu \mathrm{g} \mathrm{ml}^{-1}$ and DXR from 0 to $5 \mu \mathrm{g} \mathrm{ml}^{-1}$.

Growth of tumour cells was measured using the sulphorhodamine-B (SRB) assay (Skehan et al, 1990). In brief, cells were washed with PBS, incubated with $10 \%$ trichloric acetic acid for $1 \mathrm{~h}$ at a temperature of $-4^{\circ} \mathrm{C}$ and washed again. Cells were stained with SRB for about $15-30 \mathrm{~min}$, washed with $1 \%$ acetic acid and allowed to dry. Protein-bound SRB was dissolved in TRIS (10 mM, $\mathrm{pH}$ 9.4). Extinction was measured at $540 \mathrm{~nm}$ and the percentage of growth inhibition was calculated according to the formula: percentage of tumour cell growth $=$ (test well/control well $) \times 100 \%$. The drug concentration leading to $50 \%$ reduction in absorbance, as compared to control $\left(\mathrm{IC}_{50}\right)$, was determined from the growth curve. The experiments were repeated four times.

Human umbilical vein endothelial cells (HUVEC) were prepared by collagenase treatment of freshly obtained human umbilical veins and cultured in human endothelial-SFM/RPMI medium (Life Biotechnologies, Breda, the Netherlands) supplemented with $10 \%$ heat-inactivated human serum (Cambrex, Verviers, Belgium), $20 \%$ new born calf serum, human EGF, human bFGF and $0.1 \%$ penicillin-streptomycin (Life Technologies, the Netherlands).

Human umbilical vein endothelial cells were plated $24 \mathrm{~h}$ before treatment in 96 -well plates at $6 \times 10^{4} \mathrm{cells} \mathrm{ml}^{-1}$, total volume of $100 \mu \mathrm{l}$ and allowed to grow as a monolayer. Next, they were cultured for $48 \mathrm{~h}$ with $\mathrm{Hi}$, in concentrations ranging from 0 to $200 \mu \mathrm{g} \mathrm{ml}^{-1}$ and DXR from 0 to $0.5 \mu \mathrm{g} \mathrm{ml}^{-1}$. The growth and $\mathrm{IC}_{50}$ were determined in the same way as for the tumour cells.

\section{Statistical analysis}

Kruskal - Wallis and Mann - Whitney $U$-tests were used to evaluate statistical significance of the results. All statistical tests were twosided and $P$-values less than 0.05 were considered as statistically significant. Calculations were performed on a personal computer using Prism v3.0 software (GraphPad Software Inc., San Diego, CA, USA) and SPSS v10.0 for Windows 2000.

\section{RESULTS}

\section{Tumour response after ILP}

While tumours grew exponentially in all rats submitted to either control or DXR alone ILP, Hi alone could arrest tumour growth for 4 days in two out of seven animals (29\%). As expected, the best response was seen with the combination of Hi and DXR showing a partial regression in two animals (33\%) and arrest of tumour growth for approximately 6 days in three animals $(50 \%)(P<0.01$ on day 8 for Hi + DXR as compared to sham; $P=0.027$ on day 8 for $\mathrm{Hi}+$ DXR as compared to DXR alone) (Figure 1; Table 1).

As previously seen in $\mathrm{Hi}+$ melphalan ILP, Hi either alone or combined with DXR did not inflict systemic side effects. As for regional toxicity, we observed a very mild $(+)$ oedema in $17 \%$ (one out of six) of the rats treated by $\mathrm{Hi}+\mathrm{DXR}$ and $14 \%$ (one out of seven) of those treated by $\mathrm{Hi}$ alone ILP, leading to a temporary grade 1 toxicity. The oedema compromised the limb as whole, including both the tumour and the normal tissue and was of the soft kind oedema. Isolated limb perfusion with DXR alone also caused a temporary regional toxicity in one $(17 \%)$ of the treated rats scoring a grade 1 function with limb oedema lasting for 3-4 days.

\section{Histology}

Immediately after ILP with Hi + DXR vasodilation was observed, accompanied by tumoral endothelial cell damage and haemor-

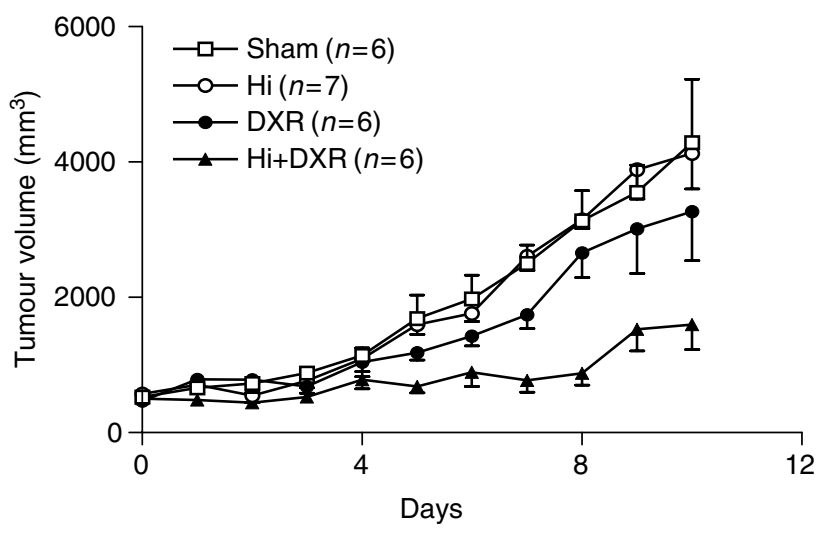

Figure I Tumour response in soft-tissue sarcoma bearing rats after Hibased ILP. Tumor-bearing rats were submitted to ILP with sham, DXR, Hi or DXR + Hi as described in Materials and Methods. Mean tumour volumes + s.e.m. are depicted. ${ }^{*} P<0.01$ on day 8 for $H i+D X R$ as compared to sham; $P=0.027$ on day 8 for $\mathrm{Hi}+\mathrm{DXR}$ as compared to $\mathrm{DXR}$ alone.

Table I Response in BN-I75 soft tissue sarcoma-bearing rats after doxorubicin-based ILP in combination with Histamine over a total period of 08 days

\begin{tabular}{llccc}
\hline Treatment $^{\mathbf{a}}$ & CR $^{\mathbf{b}}$ & PR (\%) & NC (\%) & PD (\%) \\
\hline Sham $(n=5)$ & - & - & - & 100 \\
DXR $(n=6)$ & - & - & - & 100 \\
Histamine $(n=7)$ & - & - & 29 & 71 \\
Hi+DXR $(n=6)$ & - & 17 & 50 & 33 \\
\hline
\end{tabular}

${ }^{\mathrm{a}}$ Doxorubicin (DXR, $\left.400 \mu \mathrm{g}\right)$ and Histamine $(\mathrm{Hi}, \mathrm{I} 000 \mu \mathrm{g})$ were added as boluses to the perfusate $(5 \mathrm{ml})$. ${ }^{b}$ Responses were scored as described in Materials and Methods. $\mathrm{CR}=$ complete response; $\mathrm{PR}=$ partial response; $\mathrm{NC}=$ no change; $\mathrm{PD}=$ progressive disease.

rhage. Next to that some oedema in the tumour was observed. Histamine alone ILP resulted in diffuse oedema, but much less haemorrhage was seen than with the combination of $\mathrm{Hi}+\mathrm{DXR}$. Sham (data not shown) or DXR alone ILP had no effect on vasodilation or haemorrhage and predominantly intact tumour cells and few necrotic spots were seen. In accordance to these findings, CD-31 staining clearly showed the Hi-mediated destruction of the TAV-associated endothelial cell lining, with a more striking effect observed in those tumours treated by the combination of $\mathrm{Hi}+\mathrm{DXR}$ as compared to Hi alone ILP. DXR alone ILP clearly had no effect on endothelial cell lining (Figure 2).

\section{Perls iron staining - histologic evaluation after Hi-based ILP}

In agreement with $\mathrm{HE}$ and CD-31 findings, Perl's method documented a haemorrhagic effect linked to Hi administration. Although DXR-alone-treated tumours had some iron deposits 7 days after ILP, mainly in the tumour tissue, these became more abundant after Hi alone ILP. After Hi + DXR ILP though, those iron deposits were clearly bigger and much more pronounced. As expected, iron deposits were mostly observed in the rim of the tumour and close to the vessels. The pattern was exactly the same as the one previously observed after $\mathrm{Hi}+$ melphalan ILP (data not shown). Muscle tissue from Hi-treated tumours (both with and without DXR) showed few and much smaller foci. Sham ILP had no iron deposits either in muscle or in tumour tissue. These findings further support the specific TAV-targeting action of $\mathrm{Hi}$ (Figure 3). 

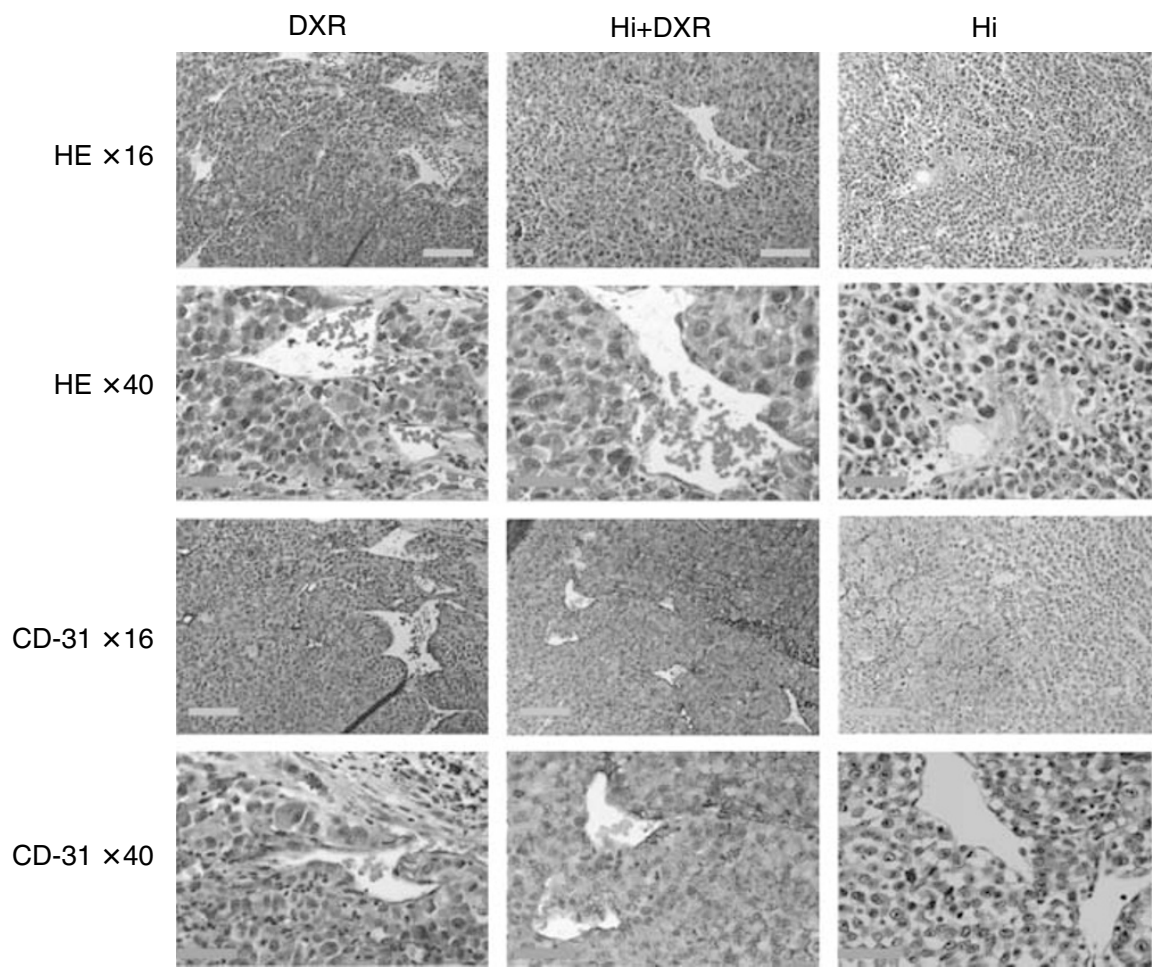

Figure 2 Tumour vascular destructive effect and haemorrhagic necrosis upon Hi-based ILP. Pictures of representative tumour histology (HE) and vascular destruction (CD3I) right after ILP with DXR, Hi or DXR + Hi are shown. Orange bar on $\times 16$ magnification pictures corresponds to $100 \mu \mathrm{m}$ and red bar on $\times 40$ magnification to $50 \mu \mathrm{m}$.

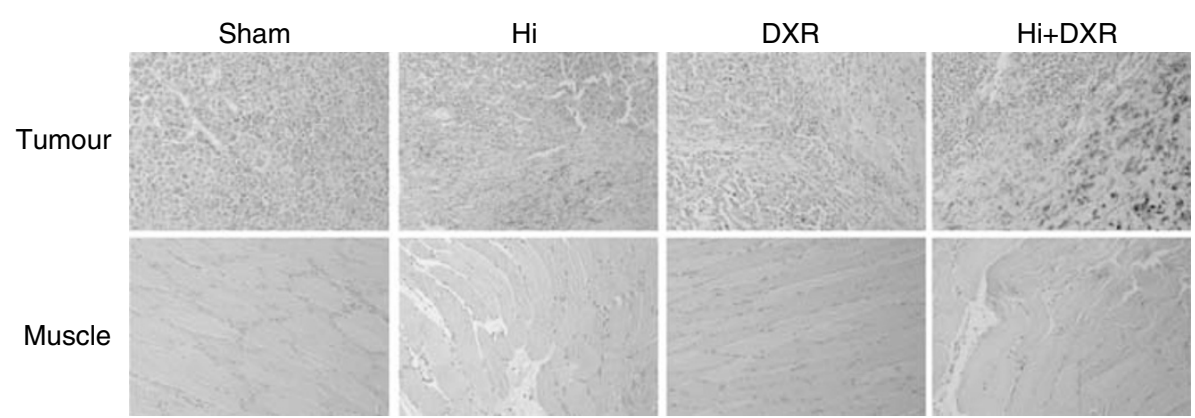

Figure 3 Staining by Perl's method shows Histamine-related induction of necrosis at 7 days after ILP, which is absent in muscle. Original magnification $\times$ 10. Black bar corresponds to $100 \mu \mathrm{m}$.

\section{Albumin extravasation and tumour endothelial cell matrix alterations}

To get a better insight into the pattern of oedema an immunohistochemistry antialbumin staining was carried out. Likewise already observed in the haematoxylin and CD-31 stainings, the vessels looked dilated after $\mathrm{Hi}$ treatment either with or without the combination to DXR. Extravasated albumin was observed around, and close to the vessels, once more, this observation was more striking after Hi + DXR ILP (Figure 4).

Given the above findings, an additional staining specific for collagen and fibrin was carried out (MSB). Apart from the already expected Hi-related vasodilation, a very interesting observation was the Hi-related disarrangement of the collagen fibres, which could possibly play a role in improving tumour drug distribution (Figure 4). Slides from adjacent muscle showed normal anatomic structures without significant changes (data not shown), further supporting the TAV-specific effect of the treatment.

\section{Doxorubicin distribution and TAV evaluation by FITC-lectin ILP}

Taking advantage of the natural red fluoresence of DXR, we evaluated drug distribution within tumour and muscle by confocal microscopy of thick slides. When ILP was performed with DXR alone, some extravasation was observed around perfused (lectinpositive) vessels. Increased extravasation of DXR was seen around tumour vessels, when $\mathrm{Hi}$ was coadministered, while in muscle no major effects were observed. Moreover, some areas of DXR leakage could be observed in the tumour, with diffuse or even absent lectin staining, indicating severe damage to the endothelial lining of the tumour vasculature. These observations suggest an increased leakage specifically from the tumour vascular bed when $\mathrm{Hi}$ was added to the ILP (Figure 5). This finding was confirmed by means of intratumoral drug distribution quantification carried out through pixels intensity measurement $(P<0.001$, DXR alone compared to DXR combined to $\mathrm{Hi}$ ). The lectin staining also 


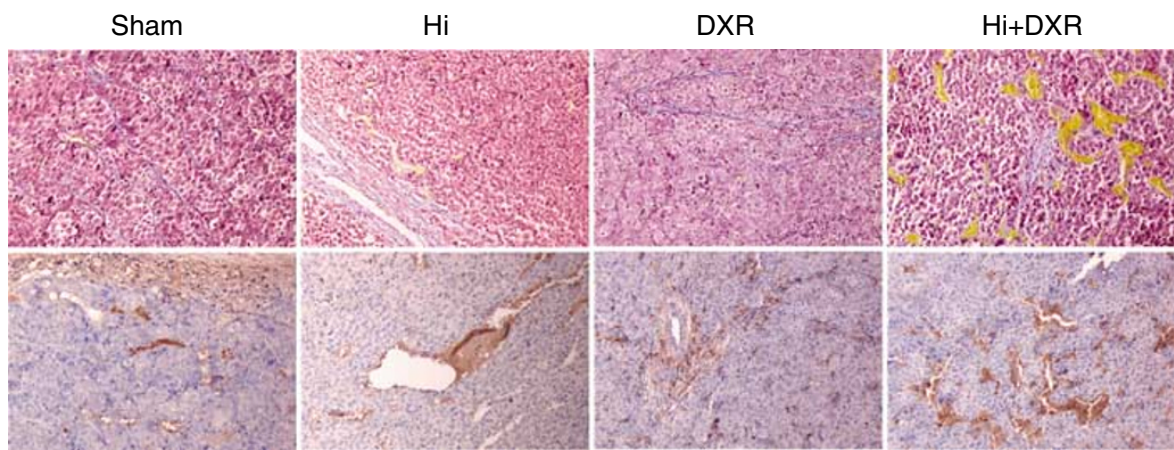

Figure 4 Albumin extravasation and tumor endothelial cell matrix alterations. Upper panel shows MSB staining for connective tissue and fibrin with a clear disarrangement of collagen fibres seen in tumours submitted to Hi-based ILP. Lower panel depicts most representative slides of Immunohistochemistry staining with antialbumin where albumin appears in brown, surrounding the vessels in the Hi-treated tumor tissues. More striking effects were clearly observed after $\mathrm{Hi}+\mathrm{DXR}$ ILP. Original magnification $\times 16$.

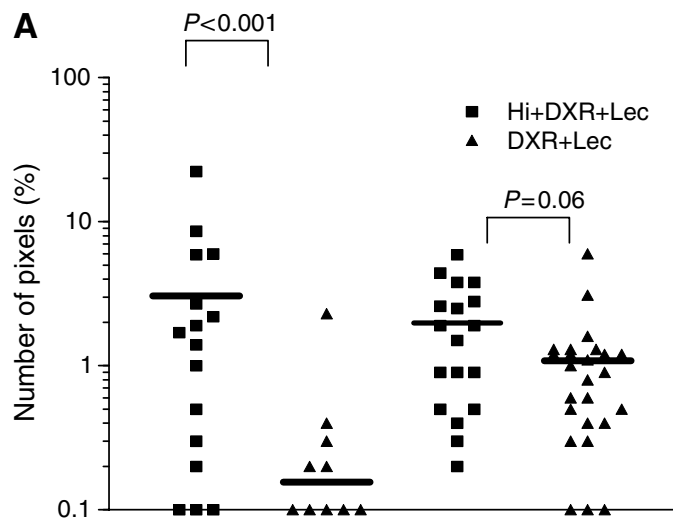

DXR

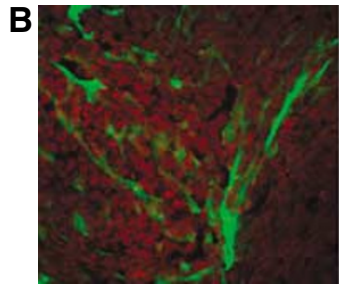

$\mathrm{DXR}+\mathrm{Lec}$

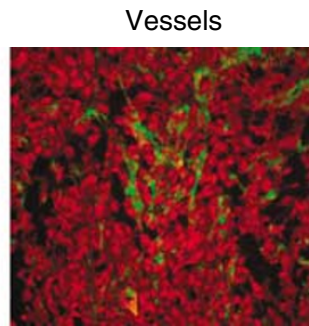

$\mathrm{Hi}+\mathrm{DXR}+\mathrm{Lec}$

Figure 5 Effect of Hi-based ILP on intratumoral DXR distribution in relation to tumour vessel presence. Directly after ILP with DXR and lectinFITC (DXR + Lec), or Histamine plus DXR and Lec $(H i+D X R+L e c)$ tumours were excised, frozen and $25 \mu \mathrm{m}$ thick slides were cut. Sections were examined by confocal microscopy. DXR distribution and vessel density in digital images were measured as described in Materials and Methods (A). Representative pictures of intratumour DXR distribution right after ILP with DXR and lectin-FITC (DXR + Lec), or histamine + DXR and Lec $(H i+D X R+L e c)$ are shown $(\mathbf{B})$.

revealed large areas devoid of functional vessels, mainly in the tumour centre, in which no DXR could be delivered during the ILP.

\section{Direct cytotoxicity of histamine}

To evaluate the potential synergistic action between DXR and $\mathrm{Hi}$, in vitro cytotoxicity assays were carried out on BN-175 tumour cells and on HUVEC. As shown in Figure 6, both agents were capable of killing endothelial cells with an $\mathrm{IC}_{50}$ of $200 \mu \mathrm{g} \mathrm{ml}^{-1}$ for $\mathrm{Hi}$ and an $\mathrm{IC}_{50}$ of $0.1 \mu \mathrm{g} \mathrm{ml}^{-1}$ for DXR. While BN-175 tumour cells were effectively killed by DXR with an $\mathrm{IC}_{50}$ of $0.08 \mu \mathrm{g} \mathrm{ml}^{-1}$, hardly
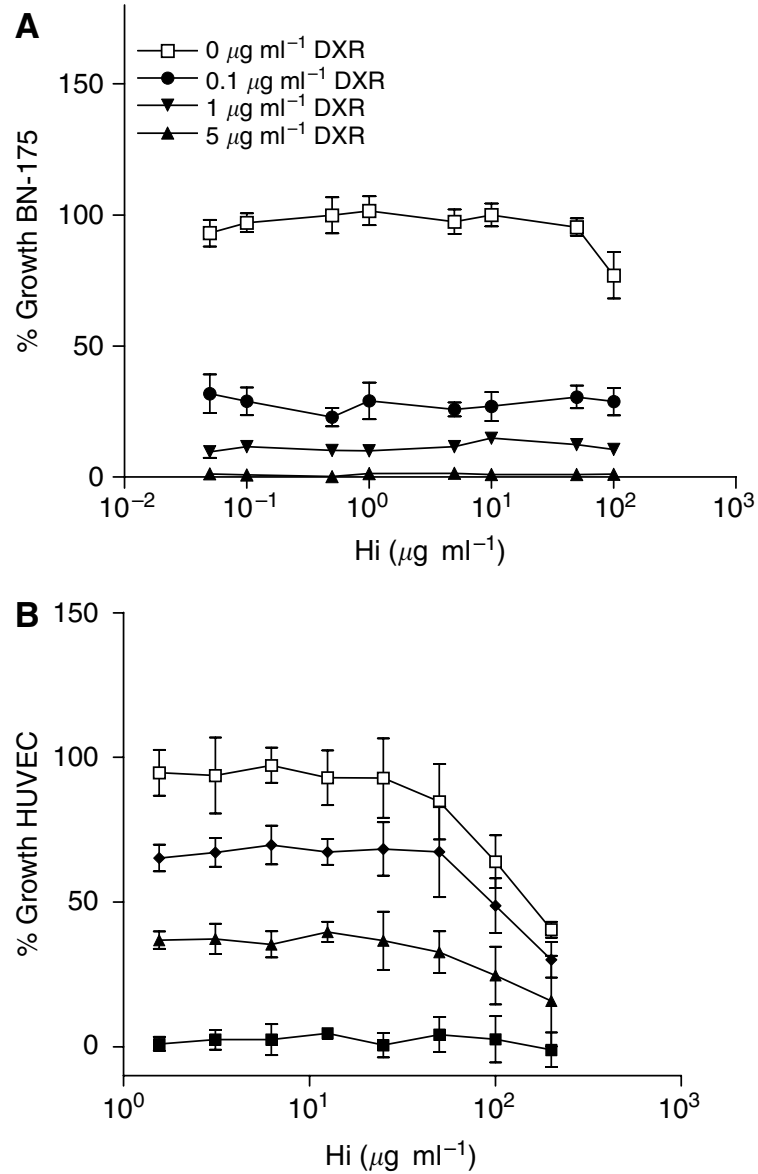

Figure 6 Evaluation of possible direct effects of $\mathrm{Hi}$ and DXR on $\mathrm{BN}-\mathrm{I} 75$ soft-tissue sarcoma cells and HUVEC. BN- 175 tumor cells (A) or HUVEC (B) were exposed to $0-5 \mu \mathrm{g} \mathrm{ml}^{-1}$ DXR with $\mathrm{Hi} 0-200 \mu \mathrm{g} \mathrm{ml}^{-1}$ for $72 \mathrm{~h}$. Each point represents an average of four readings. Error bars show s.d. values.

any effect of $\mathrm{Hi}$ was noticed with an $\mathrm{IC}_{50}$ as high as $500 \mu \mathrm{g} \mathrm{ml}^{-1}$. Combining DXR and Hi in vitro had only an additive effect.

\section{DISCUSSION}

In this study, we show, by combining the natural red fluorescence of DXR with lectin - FITC staining of functional vessels during ILP, 
that the vascular disrupting effect of Hi augments intratumoral delivery of DXR. Based on these observations we hypothesise that both destruction of the tumour-associated vasculature and better tumour drug distribution, when Hi was administered, added to the observed augmented tumour responses. Additional histological stainings, such as CD-31 and Perl's method, further demonstrated Hi-related endothelial lining disruption and tumour haemorrhage, respectively. It is of note that these effects were more intense in tumour than in the muscle tissue, in agreement with the previously reported four-fold increase in melphalan uptake by tumour as compared to muscle (Brunstein et al, 2004). Indeed, it has been long established that the susceptibility of endothelial cells to vasoactive agents vary according to their grade of differentiation. Agents such as TNF and Hi have a stimulatory effect on slowly proliferating cells from resting vessels found on normal tissue. On the other hand, fast proliferating endothelium as seen in placenta, wound tissue and tumours have an inhibitory pattern of response to vasoactive agents, and are consequently more vulnerable to haemorrhage (Denekamp, 1984; van de Wiel et al, 1992).

Histamine and TNF have many similarities concerning their mechanism of action in tumour response after ILP, including TAV targeting, with an increased tumour drug uptake accompanied by selective TAV destruction (Brunstein et al, 2004; Hoving et al, 2006). Furthermore, both $\mathrm{Hi}$ and TNF show synergistic response with chemotherapeutic drugs and both require the combination of chemotherapeutics to achieve the best tumour responses after ILP. Yet, it is of note that while a TNF-alone ILP resulted in progressive disease in all treated animals, Hi-alone ILP could arrest tumour growth in the range of $29-50 \%$ of the treated animals (this study and Brunstein et al (2004)).

Accordingly, in vitro studies disclosed a direct cytotoxic effect of $\mathrm{Hi}$ against tumour cells and endothelial cells (HUVEC), while TNF required the combination with interferon and peripheral blood mononuclear cells, for having an effect on endothelial cells in vitro (Seynhaeve et al, 2006).

Speculating on possible mechanisms of Hi-induced endothelial damage, it shall be taken into account that the gap formation of endothelial cells occurs via inositol phosphate second messenger and increased intracellular calcium concentration (Carson et al, 1989). The recovery process however, is mediated by an increased intracellular cAMP level and negative feedback inhibition, a pathway shared by 'endothelial stabilisers', such as prostaglandin (PGI2). Histamine stimulates PGI2 production after very short time incubation periods of 1-2 min (Resink et al, 1987; Wu and Baldwin, 1992) and also stimulates the production of other eicosanoids such as HETE, which can affect cell function through incorporation into membrane lipids and altering the properties of the membrane (Wang et al, 1990). Previous studies showed that HETE production reduces the production of PGI2 and leads to the contraction of the endothelial monolayer, finally compromising endothelial function and contributing to the atherogenic process (Revtyak and Campbell, 1992).

Another possible mechanism of Hi-related tumour endothelium damage could be, similarly to the one described to TNF, an induced congestion causing haemorrhage and oedema by impaired blood flow and finally resulting in haemorrhagic infarction. Supporting this theory are the different stainings documenting an Hi-related vasodilation and haemorrhage. It is already known for TNF that platelets and von Willebrand factor play a major role (Nooijen et al, 1996), yet for Hi this process still requires further investigation.

Furthermore, in this study we show that the antitumour effect of $\mathrm{Hi}$ in a regional therapy model was not restricted to melphalan but was also present in combination with DXR, resulting in tumour regressions or tumour growth arrest in $67 \%$ of the rats. Histamine alone arrested tumour growth in $29 \%$ of the animals, while tumour progression was observed in virtually all rats in sham or DXR alone groups.

Tumour response rates in this study were not as good as those previously reported for the combination of Hi plus melphalan. Yet, DXR alone was also less active than melphalan alone in our ILP model, with no antitumour effect ( $100 \%$ progressive disease) for DXR, against $17 \%$ partial response and $17 \%$ tumour growth arrest for melphalan (Brunstein et al, 2004). These findings are in accordance with the literature where melphalan is described as the drug of choice for ILP in most centres worldwide, with the best response rates and lower complication indexes (Thompson et al, 1998; de Wilt et al, 1999).

A possible explanation for the reduced efficacy of DXR could be its cycle dependency, while melphalan does not have this restriction. Taking into account that during an ILP drugs are delivered in a higher dosage but only once, apposed systemic chemotherapy where drugs are given repeatedly, this difference in activity might play an important role. Furthermore, the relatively poor penetration of DXR has already been reported as probably related to a rapid uptake of this drug by the perivascular cells. DXR binds avidly to the DNA within these cells, thus reducing the amount available for diffusion to distal cells (Primeau et al, 2005). In the case of increased permeability, due to the combination with vasoactive agents such as TNF or $\mathrm{Hi}$, DXR would still not perform as well as an alkylating agent, namely melphalan. On top of this, according to the work of Takemoto et al (2003), the alkylating reaction with cellular DNA, resulting in the formation of DNA crosslinks would be most significantly enhanced at elevated temperatures, with a reported activation energy for melphalan of $72.4 \pm 7.9 \mathrm{kcal}$, between 37 and $41^{\circ} \mathrm{C}$, which is precisely the range of temperature used in the ILP setting. These authors provided further evidence that alkylating agents are the best option for regional treatment and also elegantly showed that the drug of choice at elevated temperatures, such as those used during regional treatment, might be different from the drug of choice at the physiological temperature (Takemoto et al, 2003).

Specifically in the case of $\mathrm{Hi}$, the batch used in this study was less active in vitro on both tumour and endothelial cells as compared to previous results (Brunstein et al, 2004), and possibly resulted in a partial loss of the direct effect of Hi towards tumour and endothelial cells in vivo. Strikingly, tumour endothelial lining destruction and haemorrhage remained similar after Hi-based ILP, quite comparable to previous results. This observation was well documented by the different histologic stainings used.

An additional important finding of our study is the Hi-related disarrangement of the collagen fibres, which we speculate could play an additional role in improving tumour drug distribution. Further studies, for a better evaluation and understanding of this important step, in improving tumour response rates with the use of vasoactive drugs are underway.

In conclusion, the inflammatory mediator $\mathrm{Hi}$ acts as a vasoactive drug, targeting the tumour-associated vasculature and is capable of synergising with different chemotherapeutic agents. More importantly, this occurred without systemic side effects and only a mild regional toxicity, with a temporary limb oedema, completely reversible after 3-4 days. These findings support a potential role of $\mathrm{Hi}$ in regional treatment and organ perfusions in the clinic.

\section{ACKNOWLEDGEMENTS}

We thank Maxim Pharmaceuticals Inc., San Diego, CA, USA, for kindly providing histamine dihydrochloride injection for the studies. This study is supported by the Translational Research grant of the Erasmus MC. 


\section{REFERENCES}

Bancroft JD, Cook HC (1984) Manual of Histological Techniques and their Diagnostic Application ISBN: 0443028702

Bickels J, Manusama ER, Gutman M, Eggermont AM, Kollender Y, AbuAbid S, van Geel AN, Lev-Shlush D, Klausner JM, Meller I (1999) Isolated limb perfusion with tumour necrosis factor-alpha and melphalan for unresectable bone sarcomas of the lower extremity. Eur J Surg Oncol 25: $509-514$

Brunstein F, Hoving S, Seynhaeve AL, van Tiel ST, Guetens G, de Bruijn EA, Eggermont AM, ten Hagen TL (2004) Synergistic antitumor activity of histamine plus melphalan in isolated limb perfusion: preclinical studies. I Natl Cancer Inst 96: 1603 - 1610

Carson MR, Shasby SS, Shasby DM (1989) Histamine and inositol phosphate accumulation in endothelium: cAMP and a $\mathrm{G}$ protein. Am J Physiol 257: L259-L264

Denekamp J (1984) Vascular endothelium as the vulnerable element in tumours. Acta Radiol Oncol 23: 217-225

de Wilt JH, Manusama ER, van Tiel ST, van IJken MG, ten Hagen TL, Eggermont AM (1999) Prerequisites for effective isolated limb perfusion using tumour necrosis factor alpha and melphalan in rats. Br J Cancer 80: $161-166$

de Wilt JH, ten Hagen TL, de Boeck G, van Tiel ST, de Bruijn EA, Eggermont AM (2000) Tumour necrosis factor alpha increases melphalan concentration in tumour tissue after isolated limb perfusion. $\mathrm{Br}$ J Cancer 82: $1000-1003$

Eggermont AM, de Wilt JH, ten Hagen TL (2003) Current uses of isolated limb perfusion in the clinic and a model system for new strategies. Lancet Oncol 4: 429-437

Eggermont AM, Schraffordt KH, Klausner JM, Eggermont AM, Schraffordt Koops H, Klausner JM, Kroon BB, Schlag PM, Lienard D, van Geel AN, Hoekstra HJ, Meller I, Nieweg OE, Kettelhack C, Ben-Ari G, Pector JC, Lejeune FJ (1996a) Isolated limb perfusion with tumor necrosis factor and melphalan for limb salvage in 186 patients with locally advanced soft tissue extremity sarcomas. The cumulative multicenter European experience. Ann Surg 224: 756-764

Eggermont AM, Schraffordt KH, Lienard D, Kroon BB, van Geel AN, Hoekstra HJ, Lejeune FJ (1996b) Isolated limb perfusion with high-dose tumor necrosis factor-alpha in combination with interferon-gamma and melphalan for nonresectable extremity soft tissue sarcomas: a multicenter trial. J Clin Oncol 14: 2653-2665

Hoving S, Brunstein F, aan de Wiel-Ambagtsheer G, van Tiel ST, de Boeck G, de Bruijn EA, Eggermont AM, ten Hagen TL (2005) Synergistic antitumor response of interleukin 2 with melphalan in isolated limb perfusion in soft tissue sarcoma-bearing rats. Cancer Res 65(10): $4300-4308$

Hoving S, Seynhaeve AL, van Tiel ST, aan de Wiel-Ambagtsheer G, de Bruijn EA, Eggermont AM, ten Hagen TL (2006) Early destruction of tumor vasculature in tumor necrosis factor-alpha-based isolated limb perfusion is responsible for tumor response. Anticancer Drugs 17: 949-959

Kort WJ, Zondervan PE, Hulsman LO, Weijma IM, Westbroek DL (1984) Incidence of spontaneous tumors in a group of retired breeder female brown Norway rats. J Natl Cancer Inst 72: 709-713

Lienard D, Lejeune FJ, Ewalenko P (1992) In transit metastases of malignant melanoma treated by high dose rTNF alpha in combination with interferon-gamma and melphalan in isolation perfusion. World $J$ Surg 16: $234-240$

Nooijen PT, Manusama ER, Eggermont AM, Schalkwijk L, Stavast J, Marquet RL, de Waal RMW, Ruiter DJ (1996) Synergistic effects of TNF- alfa and melphalan in an isolated limb perfusion model of rat sarcoma: a histopathological, immunohistochemical and electron microscopical study. Br J Cancer 74: $1908-1915$

O'Byrne K, Steward WP (1999) The role of chemotherapy in the treatment of adult soft tissue sarcomas. Oncology 56: 13-23

Olieman AF, Lienard D, Eggermont AM, Kroon BB, Lejeune FJ, Hoekstra HJ, Koops HS (1999) Hyperthermic isolated limb perfusion with tumor necrosis factor alpha, interferon gamma, and melphalan for locally advanced nonmelanoma skin tumors of the extremities: a multicenter study. Arch Surg 134: 303-307

Primeau AJ, Rendon A, Hedley D, Lilge L, Tannock IF (2005) The distribution of the anticancer drug doxorubicin in relation to blood vessels in solid tumors. Clin Cancer Res 11: 8782-8788

Resink TJ, Grigorian GY, Moldabaeva AK, Danilov SM, Buhler FR (1987) Histamine-induced phosphoinositide metabolism in cultured human umbilical vein endothelial cells. Association with thromboxane and prostacyclin release. Biochem Biophys Res Commun 144: 438-446

Revtyak GE, Campbell WB (1992) Inhibition of prostaglandin synthesis in human endothelial cells treated with metabolic inhibitors. Biochim Biophys Acta 1123: 216-226

Rossi CR, Foletto M, Di Filippo F, Vaglini M, Anza' M, Azzarelli A, Pilati P, Mocellin S, Lise M (1999) Soft tissue limb sarcomas: Italian clinical trials with hyperthermic antiblastic perfusion. Cancer 86: $1742-1749$

Rossi CR, Mocellin S, Pilati P, Foletto M, Campana L, Quintieri L, De Salvo GL, Lise M (2005) Hyperthermic isolated perfusion with low-dose tumor necrosis factor $\alpha$ and doxorubicin for the treatment of limb-threatening soft tissue sarcomas. Ann Surg Oncol 12(5): 1-8

Santoro A, Tursz T, Mouridsen H, Verweij J, Steward W, Somers R, Buesa J, Casali P, Spooner D, Rankin E, Kirkpatrick A, van Glabbeke M, van Oosterom A (1995) Doxorubicin versus CYVADIC versus doxorubicin plus ifosfamide in first-line treatment of advanced soft tissue sarcomas: a randomized study of the European Organization for Research and Treatment of Cancer Soft Tissue and Bone Sarcoma Group. J Clin Oncol 13: $1537-1545$

Seynhaeve AL, Vermeulen CE, Eggermont AM, ten Hagen TL (2006) Cytokines and vascular permeability: an in vitro study on human endothelial cells in relation to tumor necrosis factor-alphaprimed peripheral blood mononuclear cells. Cell Biochem Biophys 44: $157-169$

Skehan P, Storeng R, Scudiero D, Monks A, McMahon J, Vistica D, Warren JT, Bokesch H, Kenney S, Boyd MR (1990) New colorimetric cytotoxicity assay for anticancer-drug screening. J Natl Cancer Inst 82: 1107-1112

Takemoto M, Kuroda M, Urano M, Nishimura Y, Kawasaki S, Kato H, Okumura Y, Akaki S, Kanazawa S, Asaumi J, Joja I, Hiraki Y (2003) The effect of various chemotherapeutic agents given with mild hyperthermia on different types of tumours. Int J Hyperthermia 19: 193-203

Thompson JF, Kam PC, Waugh RC, Harman CR (1998) Isolated limb infusion with cytotoxic agents: a simple alternative to isolated limb perfusion. Semin Surg Oncol 14: 238-247

van de Wiel PA, Weitenberg ES, van der PA, Bloksma N (1992) Factors that define the susceptibility of endothelial cells to tumor necrosis factor and lipid A. Immunopharmacology 23: 49-56

Wang L, Kaduce TL, Spector AA (1990) Localization of 12-hydroxyeicosatetraenoic acid in endothelial cells. J Lipid Res 31: 2265-2276

Wu NZ, Baldwin AL (1992) Possible mechanism(s) for permeability recovery of venules during histamine application. Microvasc Res 44: $334-352$ 